\title{
Current approaches to the diagnosis of vascular erectile dysfunction
}

\author{
Ming $\mathrm{Ma}^{1,2}$, Botao Yu ${ }^{1,2}$, Feng Qin ${ }^{1}$ Jiuhong Yuan ${ }^{1,2}$ \\ ${ }^{1}$ Andrology Laboratory, ${ }^{2}$ Department of Urology, West China Hospital, Sichuan University, Chengdu 610041, China \\ Contributions: (I) Conception and design: M Ma, J Yuan; (II) Administrative support: None; (III) Provision of study material or patients: None; (IV) \\ Collection and assembly of data: M Ma, B Yu, F Qin; (V) Data analysis and interpretation: All authors; (VI) Manuscript writing: All authors; (VII) \\ Final approval of manuscript: All authors. \\ Correspondence to: Jiuhong Yuan. Andrology Laboratory, West China Hospital, Sichuan University, Chengdu 610041, China; Department of Urology, \\ West China Hospital, Sichuan University, Chengdu 610041, China. Email: jiuhongyuan2107@163.com.
}

\begin{abstract}
Vascular erectile dysfunction (ED) is closely related to cardiovascular events, and early diagnosis of vascular ED may be helpful to predict the occurrence of cardiovascular events and improve prognosis. At present, there are many approaches to diagnose ED, but each method has its advantages and limitations. This study retrospectively reviewed all available literature focusing on the diagnosis of vascular ED through a systematic PubMed and EMBASE search. According to the different application scenarios, the main methods for the diagnosis of vascular ED are divided into four categories. Intra-cavernous injection of vasoactive drugs is the earliest method used in the diagnosis of vascular ED and is a basic test. For the diagnosis of arterial ED, color duplex Doppler ultrasound, selective penile angiography, magnetic resonance imaging, and computed tomography are more commonly used. While for the diagnosis of venous ED, shear wave elastography, dynamic infusion cavernosometry and cavernosography are more accurate. Endo-peripheral arterial tonometry (PAT) has also been used to detect vascular endothelial function. Although various existing examinations are widely used for the evaluation of vascular ED, they still have some shortcomings, such as invasiveness, contingency, high false positive (negative) rate. New methods of long-term dynamic detection are needed.
\end{abstract}

Keywords: Vascular erectile dysfunction (vascular ED); diagnosis; advantages; limitations

Submitted Nov 16, 2019. Accepted for publication Feb 14, 2020.

doi: $10.21037 /$ tau.2020.03.10

View this article at: http://dx.doi.org/10.21037/tau.2020.03.10

\section{Introduction}

Erectile dysfunction (ED), as defined by the National Institutes of Health Consensus Panel, refers to the situation of inability to achieve and/or maintain penile erection sufficient for satisfactory sexual performance, which is divided into psychological, organic and mixed based on the etiology $(1,2)$. With the increase of the aging population, the worldwide prevalence of ED has been predicted to reach 322 million cases by the year 2025, making it a major health problem $(3,4)$. Epidemiological surveys have shown that the incidence of ED in men younger than 40 years old is $1-10 \%$, and most of them were thought to be psychogenic
ED (5). Conversely, $40.56 \%$ of men over the age of 40 may suffered from ED, and most of them have been categorized as organic ED (6). Among men over the age of 70, the prevalence of ED ranges from $50 \%$ to $100 \%(3,7)$. Most patients with organic ED are considered to be vascular ED caused by hemodynamic disorders, which is associated with endothelial dysfunction, arterial insufficiency, and/or venous occlusive dysfunction (8).

The association between vascular ED and cardiovascular disease has been widely recognized (9). Endothelial dysfunction is a common pathology of vascular ED and cardiovascular disease, and they share common risk factors such as obesity, tobacco, lack of exercise, diabetes, 
hypertension and hyperlipidemia (10). The most widely studied association between ED and cardiovascular disease is that ED patients have increased risks of not only cardiovascular events but also coronary heart disease and stroke $(11,12)$. Also, the ED severity was regarded as the morbidity and mortality predictor of the future cardiovascular disease outcome $(11,13)$. Through the investigation of 300 patients with angiographically documented coronary artery disease, ED may become evident before angina symptoms in almost $70 \%$ of cases (14). Young men with ED had a significantly increased risk of cardiac events in the future, while ED had little effect on the prognosis of older men (11). In this situation, identifying the causes of vascular ED and ascertaining potential risk factors may help to predict the occurrence of cardiovascular events and improve prognosis. Thus, this paper mainly focused on the advantages, limitations and application scenarios of existing methods for the diagnosis of suspected vascular ED.

According to the guidelines of the International Society for Sexual Medicine and the European Association of Urology, the diagnostic procedure of ED (Figure 1) is based on the bio-psycho-social process of normal sexual function, involving psychology, endocrine, blood vessels and nervous system (15). For most patients with suspected ED, phosphodiesterase type 5 inhibitors (PDE5Is) treatment is commonly used while routine special diagnostic examinations are not recommended $(16,17)$. Further examination was performed only if the patient was ineffective to oral PDE5Is. On the contrary, as mentioned above, $\mathrm{ED}$, especially the vascular $\mathrm{ED}$, is closely related to the occurrence of cardiovascular diseases. Further specific diagnostic examinations to patients with suspected vascular ED can identify etiology and risk factors, which is beneficial to their long-term prognosis. At the same time, the normal results of vascular function are also vital for the counseling of patients with ED. It can be clearly pointed out to doctors and patients that anxiety and inappropriate medication may be the indeed causes of ED patients. At this point, doctors can be more confident in advising patients to return to PDE5Is. Despite these benefits of health management, those patients may have to spend more money and bear the risk of invasive procedures but will not change ED's treatment plan (3). Therefore, for patients with suspected vascular $\mathrm{ED}$, whether to recommend a specific diagnostic test and how to choose the most valuable one has become a dilemma.

\section{Method}

In order to detect vascular ED earlier and more accurately, this paper summarized the advantages, limitations and application scenarios of existing imaging methods. We searched the PubMed and EMBASE databases for articles from January 1980 to May 2019 with the keywords: (I) 'vascular erectile dysfunction' and 'imaging diagnosis'; (II) 'vascular ED' and 'imaging diagnosis'; (III) 'vascular impotence' and 'imaging diagnosis'. The language of the articles was limited to English. In total, eight main methods for auxiliary diagnosis of vascular ED were detected. We mainly focused on publications and landmark articles over the past decade, and other relevant articles for each diagnostic method were also retrieved and summarized. According to different application scenarios, eight main methods for auxiliary diagnosis of vascular ED are divided into four categories. The parameters, advantages, and limitations of these methods were shown in Table 1.

\section{Intra-cavernous injection of vasoactive agents}

Intra-cavernous injection of vasoactive drugs is the firstly proposed method to diagnose vascular ED and laid the foundation for all other tests. In 1982, Virag et al. reported that injection of papaverine into penile cavernous can induce an immediate penile erection and maintaining peak penile tumescence after $2-15$ min (18). Since then, papaverine and related vasoactive drugs, such as phentolamine and alprostadil, are widely used in the diagnosis and treatment of vascular ED (26-28). Those drugs can increase arterial inflow and reduce venous outflow. The dosage, sensitivity, incidence of side effect, and adverse effects were listed in Table 2. Intra-cavernous injection of vasoactive agent was considered to be a first-line treatment for ED before the introduction of oral PDE5Is in 1998, and it is still an important second-line treatment option of ED. More importantly, injection of vasoactive drugs into penile cavernous body plays a central role in the diagnosis of vascular ED (29). Ten minutes after injection into the corpus cavernosum, the length and circumference of the penis were measured, and the angle between the thigh and the penis was measured while standing. If the angle is greater than $90^{\circ}$ and the duration of erection is more than $30 \mathrm{~min}$, it suggests no vascular lesion. If the angle is less than $60^{\circ}$, it indicates the possibility of vascular ED. If the angle is between $60^{\circ}$ and $90^{\circ}$, further examinations 


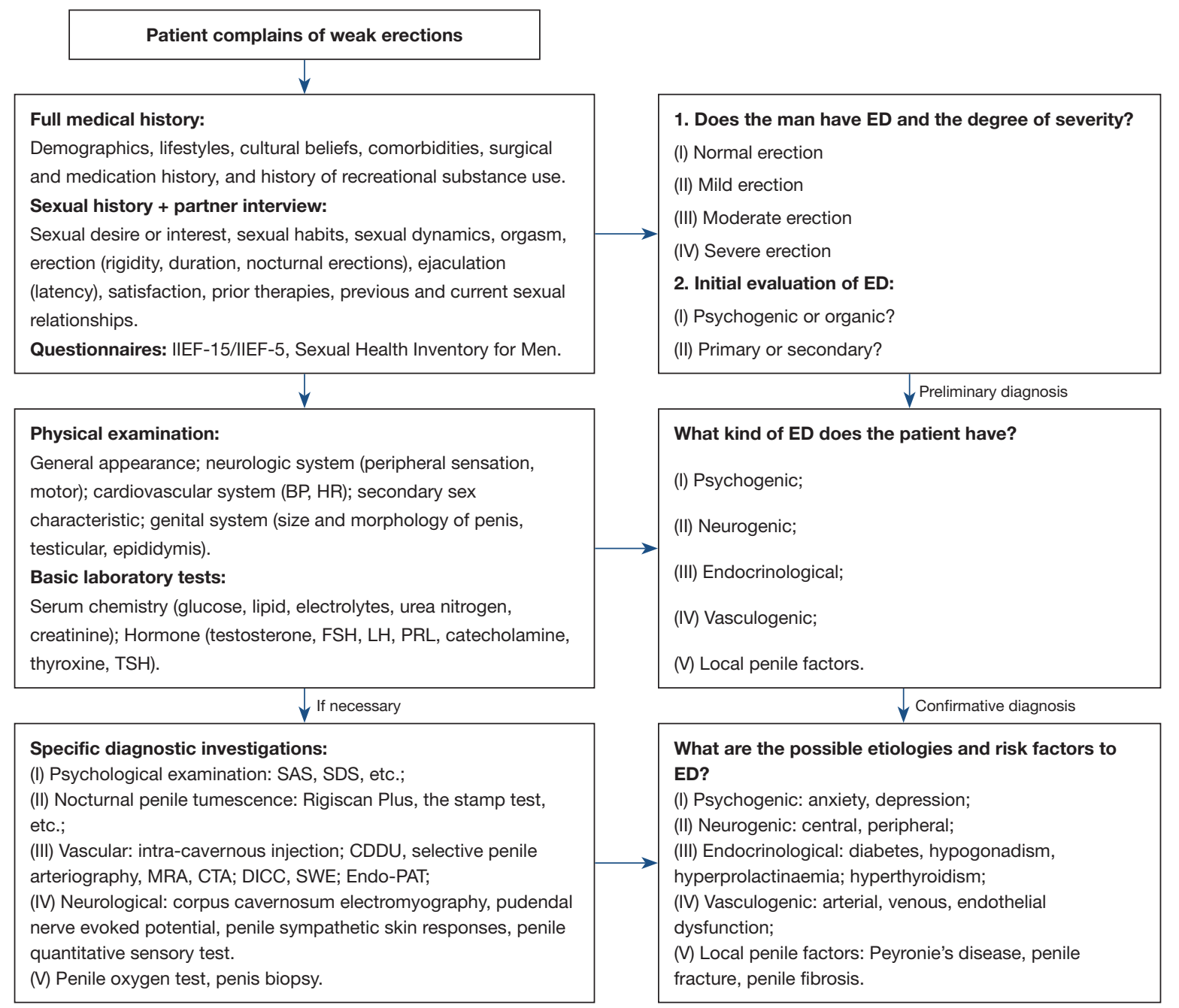

Figure 1 Full medical history, partner interview, sexual history, some standardized questionnaires are necessary to make a preliminary diagnosis. Also, physical examination and some necessary laboratory tests are required to find the possible etiology of ED. The selection of unique inspection methods should be considered to those who were suspected of vascular ED and considering surgical treatment. ED, erectile dysfunction; IIEF, international index of erectile function; BP, blood pressure; HR, heart rate; FSH, follicle-stimulating hormone; LH, luteinizing hormone; PRL, prolactin; TSH, thyroid stimulating hormone; SAS, self-rating anxiety scale; SDS, self-rating depression scale; CDDU, color duplex Doppler ultrasound; MRA, magnetic resonance arteriography; CTA, computed tomography angiography; DICC, dynamic infusion cavernosometry and cavernosography; SWE, share wave elastography; PAT, peripheral arterial tonometry.

are needed. Meanwhile, after 15 min of injection, the slow erection of the penis indicated insufficient arterial inflow. If the penis erects quickly but weakens quickly, suggesting that there may be venous occlusion dysfunction.

Intra-cavernous injection is advantageous for its simplicity, excellent repeatability, fast, and therapeutic effect. Therefore, intra-cavernous injection has been used in screening the preliminary diagnosis of ED to distinguish vascular ED from psychogenic ED (30). However, due to the fact that penile rigidity evaluation is rather subjective, distinguishing arterial ED from venous ED by this method is less effective and accurate in comparing to color duplex Doppler ultrasound (CDDU) or cavernous angiography (31). This result may be related to insufficient injection dose or anxiety caused by injection (32). Additionally, side effect/complications like pain, priapism, penile fibrosis, and prolonged refractory time result from the invasive intra-cavernous injection, inappropriate operation or dosage may restrict its further clinical application and patient acceptance (33). Hence, almost all guidelines recommend 
Table 1 Advantages and limitations of auxiliary examination methods for penile vascular function

\begin{tabular}{|c|c|c|c|c|c|c|}
\hline Methods & Author (year) & Parameters & Advantages & Limitations & Quantitative & Objective \\
\hline $\begin{array}{l}\text { Selective } \\
\text { penile } \\
\text { angiography }\end{array}$ & $\begin{array}{l}\text { Bähren et al. } \\
(20)(1988)\end{array}$ & Imaging & $\begin{array}{l}\text { Gold standard; affirmative } \\
\text { examination }\end{array}$ & $\begin{array}{l}\text { Time consuming; invasive } \\
\text { and expensive; } \\
\text { complicated operation; } \\
\text { affected by methodology; } \\
\text { requires postinterventional } \\
\text { surveillance }\end{array}$ & No & Yes \\
\hline $\begin{array}{l}\text { Magnetic } \\
\text { resonance } \\
\text { arteriography }\end{array}$ & $\begin{array}{l}\text { Dixon et al. } \\
\text { (21) (1992) }\end{array}$ & Imaging & $\begin{array}{l}\text { Almost noninvasive; } \\
\text { good at evaluate pelvic } \\
\text { structures; supplement to } \\
\text { contraindications of } \\
\text { angiography }\end{array}$ & $\begin{array}{l}\text { Expensive; non-specific } \\
\text { images; cannot detect the } \\
\text { distal pudendal and penile } \\
\text { arteries }\end{array}$ & No & Yes \\
\hline $\begin{array}{l}\text { Computed } \\
\text { tomography } \\
\text { angiography }\end{array}$ & $\begin{array}{l}\text { Kawanishi } \\
\text { et al. (22) } \\
(2001)\end{array}$ & Imaging & $\begin{array}{l}\text { Mild invasive; 3D-virtual } \\
\text { images; independent of } \\
\text { blood flow; direct detection } \\
\text { of cavernosum; indicate } \\
\text { other vascular diseases }\end{array}$ & $\begin{array}{l}\text { Expensive; complicated } \\
\text { operation; lack of } \\
\text { standardization of the } \\
\text { parameters }\end{array}$ & No & Yes \\
\hline $\begin{array}{l}\text { Share wave } \\
\text { elastography }\end{array}$ & $\begin{array}{l}\text { Turkay et al. } \\
\text { (24) (2017) }\end{array}$ & $\begin{array}{l}\text { Share wave } \\
\text { elastography value }\end{array}$ & $\begin{array}{l}\text { Non-invasive; good } \\
\text { repeatability; quantitative } \\
\text { analysis }\end{array}$ & $\begin{array}{l}\text { Lack of standardization of } \\
\text { the parameters }\end{array}$ & Yes & Yes \\
\hline Endo-PAT & $\begin{array}{l}\text { Seager et al. } \\
(25)(2013)\end{array}$ & $\begin{array}{l}\text { Augmentation index; } \\
\text { reactive hyperaemic } \\
\text { index }\end{array}$ & $\begin{array}{l}\text { Non-invasive; prediction of } \\
\text { cardiovascular disease }\end{array}$ & $\begin{array}{l}\text { Controversial; lack of } \\
\text { standardization of the } \\
\text { parameters }\end{array}$ & Yes & Yes \\
\hline
\end{tabular}

ED, erectile dysfunction; PAT, peripheral arterial tonometry.

that intra-cavernous injection be used in conjunction with other diagnostic methods, rather than applicated alone (17,34-36). Based on intra-cavernous injections, many other diagnostic techniques for vascular ED have raised. The advantages and disadvantages of those examinations and the scope of their applications would be described below.

\section{Methods for the diagnosis of arterial ED $C D D U$}

In 1980, ultrasound Doppler was first used for the hemodynamic detection of ED patients (37). In 1985, Lue TF firstly reported the use of CDDU combined 
Table 2 Characteristics of intra-cavernous injection drugs in the diagnosis of vascular erectile dysfunction

\begin{tabular}{|c|c|c|c|c|c|c|c|}
\hline Drugs & Pharmacological & Mean dose & Minimal dose & Maximal dose & Sensitivity & Side effect rate & Adverse effect \\
\hline $\begin{array}{l}\text { Papaverine + } \\
\text { Phentolamine }\end{array}$ & $\begin{array}{c}\alpha \text {-adrenergic } \\
\text { blocking agent }\end{array}$ & $15 \mathrm{mg}+0.4 \mathrm{mg}$ & $10 \mathrm{mg}+0.25 \mathrm{mg}$ & $80 \mathrm{mg}+10 \mathrm{mg}$ & $93 \%$ & $30 \%$ & \multirow{2}{*}{$\begin{array}{l}\text { Pain; anxiety; fibrosis; } \\
\text { priapism; infections; } \\
\text { ecchymosis; penile lump }\end{array}$} \\
\hline Alprostadil & $\begin{array}{l}\alpha 1 \text {-adrenergic } \\
\text { blocking agent }\end{array}$ & $12 \mu \mathrm{g}$ & $1 \mu \mathrm{g}$ & $40 \mu \mathrm{g}$ & $80 \%$ & $13 \%$ & \\
\hline
\end{tabular}

Table 3 Values and corresponding meanings of dynamic CDDU parameters

\begin{tabular}{|c|c|c|c|c|c|c|}
\hline Variables & Normal & Partial arterial & Arterial & Partial venous & Venous & Mixed \\
\hline $\mathrm{EDV}(\mathrm{cm} / \mathrm{s})$ & $<3$ & $<3$ & $<3$ & $3-6$ & $>6$ & $>6$ \\
\hline $\mathrm{RI}$ & $>0.8$ & $>0.8$ & $>0.8$ & $0.6-0.8$ & $<0.6$ & $<0.6$ \\
\hline
\end{tabular}

CDDU, color duplex Doppler ultrasound; EDV, end-diastolic velocity; PSV, peak systolic velocity; RI, resistive index.

with intra-cavernous injection for penile hemodynamic examination (19). After that, the number of studies have been conducted to optimize the procedures of CDDU combined with intra-cavernous injection. Nowadays, CDDU after intra-cavernous injection of vasoactive drugs has become a first-line method for the diagnosis of vascular ED, which can be used to determine the subtypes and severity of vascular ED (38-40).

High-resolution ultrasound can detect the anatomical structure of the penis, and pulse Doppler can detect penile blood flow. Penile blood flow index is the ratio of mean penile artery blood flow acceleration to radial artery acceleration, which is used to evaluate penile vascular function. Combined with the cavernous artery diameter, the dynamic peak systolic velocity (PSV), the end diastolic velocity (EDV) and the resistance index (RI) measured after intra-cavernous injection of vasoactive drugs are commonly used CDDU parameters to evaluate penile vascular function. According to the International Society for Sexual Medicine published standard operating procedures in 2013, the values and corresponding meanings of dynamic PSV, EDV and RI are listed in Table 3 (41). Patients with PSV greater than $30 \mathrm{~cm} / \mathrm{s}$ and EDV $<3 \mathrm{~cm} / \mathrm{s}$ were considered to have normal cavernous artery inflow, while patients with PSV $<25 \mathrm{~cm} / \mathrm{s}$ were defined as arterial insufficiency (41). The sensitivity and specificity of PSV in the diagnosis of arterial dysfunction confirmed by pudendal arteriography were $100 \%$ and $95 \%$, respectively (42). Venous occlusive dysfunction was defined as $\mathrm{PSV}>30 \mathrm{~cm} / \mathrm{s}$ with $\mathrm{EDV}>6 \mathrm{~cm} / \mathrm{s}$, and $\mathrm{RI}<0.6$.

CDDU has some limitations, such as complex, timeconsuming, expensive, and dependent on the operator. In particular, CCDU is not effective in the examination of venous $\mathrm{ED}$, especially in patients with arterial $\mathrm{ED}(43,44)$. More importantly, CDDU requires the smooth muscle to reach the maximum diastolic state in order to truly reflect vascular function, and anxiety or insufficient dose may lead to incomplete smooth muscle relaxation $(45,46)$. These limitations may render false positive results in CDDU tests. To achieve maximum smooth muscle relaxation and possible complete erectile response, redosing may be an option, but there is no consensus on whether redosing is needed, and what drugs and doses to use (47-49). It has also been reported that audiovisual sexual stimulation can be used to induce erection before CDDU or after intracavernous injections $(38,40,50)$. Combined audiovisual sexual stimulation and intra-cavernous injections would not only increase the objective response of penile erection but also improve subjective sexual arousal and satisfaction by providing a comfortable environment (40). Although there is a consensus in guidelines to use CDDU to detect dynamic parameters after intra-cavernous injections (41), recent studies have claimed that PSV in a flaccid state also has a good predictive value for arterial dysfunction $(51,52)$. A study of 1,346 male patients found that the diagnostic accuracy of PSV with $13 \mathrm{~cm} / \mathrm{s}$ as the threshold in flaccid state was more than $80 \%$ (53). While another prospective study demonstrated that none of the cutoff values, either 
10,13 or $15 \mathrm{~cm} / \mathrm{s}$, tested in flaccid state had a combined sensitivity and specificity $>80 \%$, which indicated the predicted value of PSV measured in flaccid state is low and the diagnosis is not reliable (54). In addition, due to the different anatomic location of Doppler imaging, the measured values of PSV and EDV have great variability, which often affect the clinical diagnosis (55-57). It was found that the PSV value of proximal cavernous artery was much higher than that of distal cavernous artery in both ED patients $(39.0 \pm 11.2$ vs. $20.0 \pm 5.6 \mathrm{~cm} / \mathrm{s})$ and normal controls $(39.8 \pm 8.0$ vs. $21.3 \pm 5.5 \mathrm{~cm} / \mathrm{s})(55)$. There may also be differences in PSV values between the left and right cavernous arteries (58). A difference of more than 20 percent between the two arterial regions of the penis was considered suspicious of arterial insufficiency (39). Comparing bilateral injection with unilateral injection, it was found that the PSV on the injection side was higher than that on the contralateral side, but there was no difference in bilateral PSV after bilateral injection (59). In order to reduce the variation of the test results and improve the accuracy of diagnosis, some researchers have tried to divide vasoactive drugs into two parts and inject them into the left and right penile (60). However, the sample size is small, and more research is needed on whether bilateral injection is needed. The measurement of the level of the penoscrotal junction may be useful for the detection of venous occlusion dysfunction, while the evaluation at the $1 / 2$ distance between penoscrotal junction and coronal sulcus may be helpful in the diagnosis of arterial insufficiency (59).

Generally speaking, CDDU has been widely accepted as a first-line diagnostic method for vascular ED. However, due to the different proficiency of operators, and the lack of unified standards to regulate the anatomical site of examination, whether to use drugs, whether to use audiovisual sexual stimulation to induce erection, there are differences between different research results. Future guidelines will need to develop more detailed and standardized operating procedures and determine the new specification values required for each location. Besides, more experiments are needed to prove the accuracy of PSV in the diagnosis and prediction of vascular ED under flaccid state.

\section{Selective penile angiography}

CDDU is an ideal method for preliminary assessment of penile vascular function, while it is highly dependent on the observer, and only evaluates the vascular function but fails to provide anatomical information (61). In this situation, selective penile angiography, which remains the "gold standard" method in the diagnosis of all types of vasculogenic ED, is considered to be a three-line method (62). Penile angiography can accurately and directly depict the pelvic and penile vasculature, and it can detect traumatic arterial injury, anatomical variations, steno-occlusive disease, and collateral networks in patients with the suspected vasculogenic disease (63). It is typically reserved for young patients with suspected arterial ED and being considered for revascularization surgery (20).

Although penile angiography has been recognized as the gold standard for effective assessment of vascular ED, there are some drawbacks. It is invasive, costly and requires postinterventional surveillance. Besides, the complex operations require an interventional radiologist skilled at cannulating the small internal pudendal arteries.

\section{Magnetic resonance arteriography (MRA)}

MRA is a relatively new technique, which uses the transient shortening of $\mathrm{T} 1$ weighted relaxation time of blood following intravenous injection of gadolinium chelates to image blood vessels (21). Because of the given proximity between the prostate and the genitals, penile anatomy and vasculature are often depicted on these imaging studies. Hence, magnetic resonance imaging had been widely used to evaluate post-traumatic impotence, penile prosthesis, penile fracture, or fibrous plaques in Peyronie's disease (64-66).

According to John et al., the proximal iliac and pudendal arteries were reliably delineated with MRA, while evaluation of the distal pudendal and penile arteries was limited (61). They concluded that the conventional selective penile angiography remains superior to the three-dimensional (3D) MRA for the assessment of the distal portions of penile arteries, and the 3D MRA cannot be recommended for routine preoperative planning of revascularization. Since the MRA is an almost noninvasive diagnostic method which can provide multi-angle and high-resolution assessment and less complex operations, it may be a supplement to patients with contraindications of angiography.

\section{Computed tomography angiography (CTA)}

With the rapid development of multi-slice computed tomography (CT) technology, the quality of CTA has been improved remarkably. High-quality CTA is equivalent to previous results obtained only by selective penile 
angiography, and is faster and less invasive (22). Besides, CT and magnetic resonance imaging data can be used for virtual endoscope image reconstruction. Virtual endoscopy was first used in the field of colonoscopy and later extended to other organs, such as bronchus, bladder, ureter, and pharynx (67-71). At present, virtual endoscopy can be used not only in clinical diagnosis but also in the study of anatomical structure (72). After cavernosography, forty patients underwent 3D-CT examination, and the virtual endoscopic images of cavernous body were reconstructed according to 3D-CT data (73). Not only the cavernous septum can be observed, but also the blood flow signals of arterial inflow and venous outflow can be observed respectively. Vascular examination was performed in 55 patients with ED who were ineffective to oral PDE5I, and 45 patients were diagnosed as venous occlusive dysfunction by dynamic infusion cavernosometry and cavernosography (DICC). 3D-CT cavernosography also diagnosed these patients and showed the venous drainage system and the location of venous leakage more clearly and accurately (74). The development of CTA and the virtual endoscopic images provided a unique and novel method to evaluate the etiology of ED, which is an outpatient examination. However, more randomized controlled clinical trials are needed to prove the accuracy and reliability of this promising method.

\section{Methods for the diagnosis of venous ED}

\section{DICC}

The main mechanism of penile erection is the infusion of arteries and occlusion of venous vessels. Although intracavernous injections and CDDU are of certain value in the evaluation of vascular ED, especially the arterial ED, they are not effective and specific examination methods to determine venous function directly (62). DICC, which has been considered as the gold standard test to assess both arterial and venous ED (75), includes cavernosometry and cavernosography. Cavernosometry is used to detect the function of cavernous vessels (76), while cavernosography can directly reflex the venous reflux and observe the existence of venous leakage (23), which is of unique value in the diagnosis of venous ED.

At present, DICC is usually performed for patients suspected with venous ED or those who are about to undergo surgery to understand the location and extent of venous fistulas $(17,31,34,35)$. Ten minutes after the first dose of the medication, the induced flow, maintain flow, and the pressure decay are recorded (77). Before vasoactive drugs been used to induce penile erection, the normal value of the induced flow ranged from $90 \mathrm{~mL} / \mathrm{min}$ to $105 \mathrm{~mL} / \mathrm{min}$ (depending on the size of the penis, mean value of $95 \mathrm{~mL} / \mathrm{min}$ ); the maintain flow ranged from 55 to $65 \mathrm{~mL} / \mathrm{min}$ (about $60 \%$ of the initial erectile rate, mean value of $62 \mathrm{~mL} / \mathrm{min}$ ). Venous occlusion dysfunction may be considered when the maintain flow exceeds $120 \mathrm{~mL} / \mathrm{min}$, and venous leakage may be diagnosed when the induced flow is greater than $120 \mathrm{~mL} / \mathrm{min}$ and the maintain flow is greater than $50 \mathrm{~mL} / \mathrm{min}$. The ratio of induced flow to maintain flow and the pressure decay are now considered to be better indicators of penile venous function, especially the presence and severity of venous leakage. In a previous study, arterial insufficiency was diagnosed when cavernous artery occlusion pressure was greater than $30 \mathrm{mmHg}$, and venous leakage was diagnosed when the maintain flow is greater than $3 \mathrm{~mL} / \mathrm{min}$ and/or the pressure decay was greater than $45 \mathrm{mmHg}$ (78). At present, we usually use the maintain flow less than $20 \mathrm{~mL} / \mathrm{min}$ and the pressure decay less than $40 \mathrm{mmHg}$ as the normal standard.

Nevertheless, the positive predictive value of DICC still needs to be assessed (79). Because there is physical venous reflux when the penis is flaccid, and the vein is compressed and closed under normal erections, this procedure should be performed when the penis fully erected. Unfortunately, because anxiety or sympathetic excitement restricts the smooth muscle relaxation of the penis, even up to now, it is not possible to record if there is a complete smooth muscle relaxation even after the intra-cavernous injection of a vasoactive drug and sexual stimulation $(49,78,79)$. It is still unknown how many normal potent men in the general population would test positive for the so-called venous leak. Besides, bleeding, edema, infection, priapism are potential side effects that resulted from puncture. DICC should not be primarily used to establish a physical etiology for ED, which should be performed at certain times. That is, patients with venous occlusion dysfunction or patients whose oral and local treatment is ineffective and planned reconstructive surgery. To minimize side effects when conducting this examination, selecting eligible patients before the operation is essential, and the penis should be induced to be fully erected by audiovisual sexual stimulation, active vascular agents, or combination. 


\section{Shear wave elastography}

Ultrasound elastography is an imaging technology sensitive to tissue stiffness, which has been further developed and refined in recent years to enable quantitative assessments of tissue stiffness (80). Shear waves travel faster in stiffer tissue and slower in softer tissue. In recent years, share wave elastography (SWE) has been widely used to evaluate the tissue hardness of hepatic fibrosis, breast and thyroid lesions (81). Some studies in healthy people and ED patients have shown that SWE can detect the hardness of penile erection to evaluate erectile function (24). The smaller SWE value represents harder hardness of penis. At the same time, it can also detect the SWE value at different times to identify the existence of arteriovenous dysfunction. Due to venous leakage of these ED patients, the SWE values of the corpus cavernosum increased with time in the erectile state (82). SWE can reproducibly and quantitatively evaluate rigidity changes in penile erection. More studies are needed to establish the standard operating procedures and diagnostic parameters.

\section{Endothelial function}

Vascular microenvironment is indispensable in hemostasis, inflammation and metabolism, as well as cancer and metastasis, which is mediated by organ-specific differentiated endothelial cells (83). Vascular endothelial dysfunction is considered to be one of the predictors of cardiovascular disease, and peripheral vasodilation response is associated with endothelial dysfunction and adverse cardiac events (84). The Endo-PAT2000 (Itamar Medical, Caesarea, Israel) is a peripheral arterial tonometry (PAT) used to measure ischemic response of endothelial, which has been proved to be a non-invasive assessment of peripheral vascular function and useful for the identification of patients at risk for cardiovascular disease (85). The reactive hyperaemic index was used to detect the changes of during reactive hyperemia (86). Simply put, the baseline data were measured for $5 \mathrm{~min}$, and then relieve the pressure after pressurizing and blocking the brachial artery for $5 \mathrm{~min}$. The pressurized pressure was $60 \mathrm{mmHg}$ higher than the baseline systolic blood pressure or at least $200 \mathrm{mmHg}$ lasted $5 \mathrm{~min}$ until PAT was zero. Then, deflate the cuff and continue recording PAT tracking for $6 \mathrm{~min}$. The ratio of the PAT signal to the baseline after the cuff is released is calculated by the computer algorithm of automatically normalizing the baseline signal and indexed to the opposite arm (87). Endo-
PAT2000 was used to observe the reactive hyperaemic index and the augmentation index. The augmentation index is used to estimate arterial stiffness.

The Endo-PAT2000 is a simple and non-invasive test, which is not operator dependent and able to reflect the endothelial dysfunction. Many studies have proved it has the ability to identify those patients with higher cardiovascular risk $(85,87)$. However, the role of Endo-PAT in the diagnosis of ED is controversial. In patients with vascular ED diagnosed with CDDU, measurement of endothelial function by Endo-PAT2000 can distinguish between men with vascular ED and men without angiogenic ED (88). While another study found that Endo-PAT did not reliably predict the results of penile CDDU (25). In another study, compared the Endo-PAT scores of 194 patients with general ED and 98 patients with ED after prostatectomy, it was also found that there was no difference between the EndoPAT scores and the etiological types of ED patients (89). Therefore, it is considered that neither reactive hyperaemic index nor augmentation index measured by Endo-PAT can effectively predict EDV or PSV measured by CDDU, so Endo-PAT cannot replace CDDU in the diagnosis of vascular ED. However, the relationship between CDDU and Endo-PAT is worth of consideration because they measure potentially complementary aspects of the local and systemic vasculature and, together, may provide a more complete picture of the etiology of disease as well as of systemic risks (89). The role of Endo-PAT in the diagnosis of vascular ED requires higher quality clinical trials.

Intra-cavernous injection of vasoactive agent, CDDU, selective penile angiography, and DICC are commonly used in vascular examination to distinguish arterial insufficiency from venous occlusion dysfunction and other causes of ED. SWE, MRA, CTA, and the virtual cavernoscopy following reconstruction of $3 \mathrm{D}-\mathrm{CT}$ are emerging methods due to the continuous improvement and updating of the detection technology. Endo-PAT was indirect detection method to evaluate the vascular function of the penis. Doctors and patients can use this information to make shared clinical decisions. It is also useful in cases of suspected psychogenic $\mathrm{ED}$, and normal results can alleviate anxiety in patients. However, all eight existing methods have limitations, such as invasiveness, high rates of false positive (negative). At the same time, the principle and structure of the current inspection equipment are relatively complex, which requires trained medical professionals to operate. Hence, the operating procedures and evaluation criteria of existing methods need to be continuously optimized and unified. 
In addition, some new methods are also needed and encouraged.

\section{Prospective diagnostic method}

The existing imaging equipment has been able to perform a more comprehensive examination and evaluation of the structure and function of penile blood vessels, which provides an essential basis for doctors to diagnose vascular ED and determine the follow-up treatment plan. However, it can be seen from the above that there are still some deficiencies in the existing auxiliary examination methods. At the same time, the current examination methods can only reflect the instantaneous or a short period of time, and cannot carry out long-term dynamic monitoring of patients, which may not reflect the true condition of the patient. In this situation, wearable devices based on the Internet of Things may be an option.

With the rapid development of micro-sensors and Internet data analysis, wearable devices are more and more widely used in continuous dynamic monitoring of health data. Using a wearable surface electromyography (EMG) device detects the generalized tonic-clonic seizure, the sensitivity exceeds $90 \%$ and the detection latency was within 30 seconds (90). In addition, wearable devices have been proved to be able to detect cardiac rhythms to identify arrhythmias early (91-93). Similar to the principle of these wearable devices, new methods of long-term dynamic detection of erectile function are needed (94). During penile erection, increased arterial blood inflow leads to an increase in oxygen saturation, so monitoring oxygen saturation can reflect the function of penile blood vessels. Besides, detecting the frequency, hardness and duration of spontaneous erection at night are essential for the diagnosis of ED. Psychological ED can be identified by monitoring nocturnal erection. The speed of erection can reflect the function of the artery, while the maintenance time and the rate of weakness can reflect the function of the vein. A deep neural network can be trained with these data. When the long-term monitoring results are abnormal, early intervention is needed. The curative effect can be evaluated by comparing the changes of indexes before and after the intervention. Based on data analysis, different diagnostic criteria can also be proposed for patients of different ages and different causes. With the increase of data, the sensitivity and specificity of diagnosis will increase correspondingly. In theory, it is non-invasive, objective, long-term, and real-time.

\section{Conclusions}

In the subclinical stage of cardiovascular disease, the main pathology is vascular endothelial dysfunction. Penile artery is a small artery, early hemodynamic changes can lead to vascular ED, with the progress of the disease, many cardiovascular diseases manifested gradually, such as coronary heart disease and stroke. Therefore, vascular structure and function tests in patients with ED to identify angiogenic ED and potential cardiovascular risk factors play a vital role in the management of the disease. When evaluating ED patients, the corresponding examinations can be selected according to the needs. Intra-cavernous injection of vasoactive drugs is a basic test. CDDU, selective penile angiography, MRA, and CTA are more commonly used for the diagnosis of arterial ED. While for the diagnosis of venous ED, SWE and DICC are more accurate. Besides, Endo-PAT has also been used to detect vascular endothelial function. The operating procedures and evaluation criteria of existing methods need to be optimized and unified. In addition, some new methods are also needed and encouraged.

\section{Acknowledgments}

Funding: This work was supported by the Natural Science Foundation of China (No. 81671453 and No. 81871147), the Sichuan Science and Technology Program (No. 2018SZ0019 and No. 2018TJPT0018), and the 1.3 .5 project for disciplines of excellence-Clinical Research Incubation Project, West China Hospital of Sichuan University (2019HXFH015).

\section{Footnote}

Conflicts of Interest: All authors have completed the ICMJE uniform disclosure form (available at http:// dx.doi.org/10.21037/tau.2020.03.10). FQ and JY have the patent INTELLIGENT MONITOR OF ERECTILE FUNCTION issued. The other authors have no conflicts of interest to declare.

Ethical Statement: The authors are accountable for all aspects of the work in ensuring that questions related to the accuracy or integrity of any part of the work are appropriately investigated and resolved.

Open Access Statement: This is an Open Access article 
distributed in accordance with the Creative Commons Attribution-NonCommercial-NoDerivs 4.0 International License (CC BY-NC-ND 4.0), which permits the noncommercial replication and distribution of the article with the strict proviso that no changes or edits are made and the original work is properly cited (including links to both the formal publication through the relevant DOI and the license). See: https://creativecommons.org/licenses/by-nc$\mathrm{nd} / 4.0 \%$.

\section{References}

1. NIH Consensus Conference. Impotence. NIH consensus development panel on impotence. JAMA 1993;270:83-90.

2. Montorsi F, Adaikan G, Becher E, et al. Summary of the recommendations on sexual dysfunctions in men. J Sex Med 2010;7:3572-88.

3. Shamloul R, Ghanem H. Erectile dysfunction. Lancet 2013;381:153-65.

4. Ayta IA, McKinlay JB, Krane RJ. The likely worldwide increase in erectile dysfunction between 1995 and 2025 and some possible policy consequences. BJU Int 1999;84:50-6.

5. Nguyen HMT, Gabrielson AT, Hellstrom WJG. Erectile dysfunction in young men-a review of the prevalence and risk factors. Sex Med Rev 2017;5:508-20.

6. Zhang X, Yang B, Li N, et al. Prevalence and risk factors for erectile dysfunction in chinese adult males. J Sex Med 2017;14:1201-8.

7. Nicolosi A, Moreira ED Jr, Shirai M, et al. Epidemiology of erectile dysfunction in four countries: cross-national study of the prevalence and correlates of erectile dysfunction. Urology 2003;61:201-6.

8. Uddin SMI, Mirbolouk M, Dardari Z, et al. Erectile Dysfunction as an Independent Predictor of Future Cardiovascular Events. Circulation 2018;138:540-2.

9. Bai Q, Xu QQ, Jiang H, et al. Prevalence and risk factors of erectile dysfunction in three cities of China: a community-based study. Asian J Androl 2004;6:343-8.

10. Ponholzer A, Temml C, Mock K, et al. Prevalence and risk factors for erectile dysfunction in 2869 men using a validated questionnaire. Eur Urol 2005;47:80-5.

11. Inman BA, Sauver JL, Jacobson DJ, et al. A populationbased, longitudinal study of erectile dysfunction and future coronary artery disease. Mayo Clin Proc 2009;84:108-13.

12. Dong JY, Zhang YH, Qin LQ. Erectile dysfunction and risk of cardiovascular disease: meta-analysis of prospective cohort studies. J Am Coll Cardiol 2011;58:1378-85.
13. Papagiannopoulos D, Khare N, Nehra A. Evaluation of young men with organic erectile dysfunction. Asian J Androl 2015;17:11-6.

14. Montorsi F, Briganti A, Salonia A, et al. Erectile dysfunction prevalence, time of onset and association with risk factors in 300 consecutive patients with acute chest pain and angiographically documented coronary artery disease. Eur Urol 2003;44:360-4.

15. Prieto D. Physiological regulation of penile arteries and veins. Int J Impot Res 2008;20:17-29.

16. McMahon CG. Current diagnosis and management of erectile dysfunction. Med J Aust 2019;210:469-76.

17. Burnett AL, Nehra A, Breau RH, et al. Erectile dysfunction: AUA guideline. J Urol 2018;200:633-41.

18. Virag R. Intracavernous injection of papaverine for erectile failure. Lancet 1982;2:938.

19. Lue TF, Hricak H, Marich KW, et al. Vasculogenic impotence evaluated by high-resolution ultrasonography and pulsed Doppler spectrum analysis. Radiology 1985;155:777-81.

20. Bähren W, Gall H, Scherb W, et al. Arterial anatomy and arteriographic diagnosis of arteriogenic impotence. Cardiovasc Intervent Radiol 1988;11:195-210.

21. Dixon CM, Hricak H, McAninch JW. Magnetic resonance imaging of traumatic posterior urethral defects and pelvic crush injuries. J Urol 1992;148:1162-5.

22. Kawanishi Y, Lee KS, Kimura K, et al. Feasibility of multislice computed tomography in the diagnosis of arteriogenic erectile dysfunction. BJU Int 2001;88;390-5.

23. Velcek D, Evans JA. Cavernosography. Radiology 1982;144:781-5.

24. Turkay R, Inci E, Yenice MG, et al. Shear wave elastography: Can it be a new radiologic approach for the diagnosis of erectile dysfunction? Ultrasound 2017;25:150-5.

25. Seager CM, Li J, Shoskes DA. Lack of predictive correlation between peripheral arterial tone and colour flow Doppler parameters in men with erectile dysfunction. BJU Int 2013;112:E186-90.

26. Juenemann KP, Lue TF, Abozeid M, et al. Blood gas analysis in drug-induced penile erection. Urol Int 1986;41:207-11.

27. Juenemann KP, Lue TF, Fournier GR Jr, et al. Hemodynamics of papaverine- and phentolamine-induced penile erection. J Urol 1986;136:158-61.

28. Montorsi F, Salonia A, Zanoni M, et al. Current status of local penile therapy. Int J Impot Res 2002;14 Suppl 1:S70-81. 
29. Brindley GS. Cavernosal alpha-blockade: a new technique for investigating and treating erectile impotence. Br J Psychiatry 1983;143:332-7.

30. Belew D, Klaassen Z, Lewis RW. Intracavernosal injection for the diagnosis, evaluation, and treatment of erectile dysfunction: a review. Sex Med Rev 2015;3:11-23.

31. Hatzimouratidis K, Amar E, Eardley I, et al. Guidelines on male sexual dysfunction: erectile dysfunction and premature ejaculation. Eur Urol 2010;57:804-14.

32. Tang J, Tang Y, Dai Y, et al. The use of intracavernous injection and audiovisual sexual stimulation during real-time pharmacopenile doppler ultrasonography in vasculogenic erectile dysfunction. Urol Int 2013;90:460-4.

33. Nelson CJ, Hsiao W, Balk E, et al. Injection anxiety and pain in men using intracavernosal injection therapy after radical pelvic surgery. J Sex Med 2013;10:2559-65.

34. Hackett G, Kirby M, Wylie K, et al. British society for sexual medicine guidelines on the management of erectile dysfunction in men-2017. J Sex Med 2018;15:430-57.

35. Bella AJ, Lee JC, Carrier S, et al. 2015 CUA Practice guidelines for erectile dysfunction. Can Urol Assoc J 2015;9:23-9.

36. Hatzimouratidis K, Salonia A, Adaikan G, et al. Pharmacotherapy for erectile dysfunction: recommendations from the Fourth International Consultation for Sexual Medicine (ICSM 2015). J Sex Med 2016;13:465-88.

37. Velcek D, Sniderman KW, Vaughan ED, et al. Penile flow index utilizing a Doppler pulse wave analysis to identify penile vascular insufficiency. J Urol 1980;123:669-73.

38. Montorsi F, Guazzoni G, Barbieri L, et al. The effect of intracorporeal injection plus genital and audiovisual sexual stimulation versus second injection on penile color Doppler sonography parameters. J Urol 1996;155:536-40.

39. Aversa A, Sarteschi LM. The role of penile color-duplex ultrasound for the evaluation of erectile dysfunction. J Sex Med 2007;4:1437-47.

40. Katlowitz NM, Albano GJ, Morales P, et al. Potentiation of drug-induced erection with audiovisual sexual stimulation. Urology 1993;41:431-4.

41. Sikka SC, Hellstrom WJ, Brock G, et al. Standardization of vascular assessment of erectile dysfunction: standard operating procedures for duplex ultrasound. J Sex Med 2013;10:120-9.

42. Quam JP, King BF, James EM, et al. Duplex and color Doppler sonographic evaluation of vasculogenic impotence. AJR Am J Roentgenol 1989;153:1141-7.

43. Cavallini G, Maretti C. Unreliability of the duplex scan in diagnosing corporeal venous occlusive disease in young healthy men with erectile deficiency. Urology 2018;113:91-8.

44. Golijanin D, Singer E, Davis R, et al. Doppler evaluation of erectile dysfunction - part 2. Int J Impot Res 2007;19:43-8.

45. Hatzichristou DG, Saenz de Tejada I, Kupferman S, et al. In vivo assessment of trabecular smooth muscle tone, its application in pharmaco-cavernosometry and analysis of intracavernous pressure determinants. J Urol 1995;153:1126-35.

46. Saenz de Tejada I, Moroukian P, Tessier J, et al. Trabecular smooth muscle modulates the capacitor function of the penis. Studies on a rabbit model. Am J Physiol 1991;260:H1590-5.

47. Arafa M, Eid H, Shamloul R. Significance of phentolamine redosing during prostaglandin E1 penile color Doppler ultrasonography in diagnosis of vascular erectile dysfunction. Int J Urol 2007;14:476-7.

48. Mulhall JP, Abdel-Moneim A, Abobakr R, et al. Improving the accuracy of vascular testing in impotent men: correcting hemodynamic alterations using a vasoactive medication re-dosing schedule. J Urol 2001;166:923-6.

49. Teloken PE, Park K, Parker M, et al. The false diagnosis of venous leak: prevalence and predictors. J Sex Med 2011;8:2344-9.

50. Kuo YC, Liu SP, Chen JH, et al. Feasability of a novel audio-video sexual stimulation system: an adjunct to the use of penile duplex Doppler ultrasonography for the investigation of erectile dysfunction. J Sex Med 2010;7:3979-83.

51. Hsiao W, Shrewsberry AB, Moses KA, et al. Longer time to peak flow predicts better arterial flow parameters on penile Doppler ultrasound. Urology 2010;75:112-6.

52. Souper R, Hartmann J, Alvarez M, et al. Correlation between peak systolic velocity and diameter of cavernosal arteries in flaccid versus dynamic state for the evaluation of erectile dysfunction. Int J Impot Res 2017;29:132-5.

53. Corona G, Fagioli G, Mannucci E, et al. Penile doppler ultrasound in patients with erectile dysfunction (ED): role of peak systolic velocity measured in the flaccid state in predicting arteriogenic ED and silent coronary artery disease. J Sex Med 2008;5:2623-34.

54. Kahvecioğlu N, Kurt A, Ipek A, et al. Predictive value of cavernosal peak systolic velocity in the flaccid penis. Adv Med Sci 2009;54:233-8.

55. Kim SH, Paick JS, Lee SE, et al. Doppler sonography of deep cavernosal artery of the penis: variation of 
peak systolic velocity according to sampling location. J

Ultrasound Med 1994;13:591-4.

56. Pagano MJ, Stahl PJ. Variation in penile hemodynamics by anatomic location of cavernosal artery imaging in penile duplex Doppler ultrasound. J Sex Med 2015;12:1911-9.

57. Pezzoni F, Scroppo FI. Penile vascular diagnostic categorization using penile duplex Doppler ultrasound: Differences in vascular hemodynamics parameters by differences in anatomic sampling location. Arch Ital Urol Androl 2016;88:183-5.

58. Yang Y, Hu JL, Ma Y, et al. Pharmaco-induced erections for penile color-duplex ultrasound: oral PDE5 inhibitors or intracavernosal injection? Int J Impot Res 2012;24:191-5.

59. Ghafoori M, Hoseini K, Shakiba M. Comparison of oneside and bilateral intracavernosal papaverine injection on a Doppler study of the penis. Int J Impot Res 2009;21:382-6.

60. Mutnuru PC, Ramanjaneyulu HK, Susarla R, et al. Pharmaco Penile Duplex Ultrasonography in the Evaluation of Erectile Dysfunction. J Clin Diagn Res 2017;11:TC07-10.

61. John H, Kacl GM, Lehmann K, et al. Clinical value of pelvic and penile magnetic resonance angiography in preoperative evaluation of penile revascularization. Int J Impot Res 1999;11:83-6.

62. Montague DK, Jarow JP, Broderick GA, et al. Chapter 1: The management of erectile dysfunction: an AUA update. J Urol 2005;174:230-9.

63. Rajfer J, Canan V, Dorey FJ, et al. Correlation between penile angiography and duplex scanning of cavernous arteries in impotent men. J Urol 1990;143:1128-30.

64. Armenakas NA, McAninch JW, Lue TF, et al. Posttraumatic impotence: magnetic resonance imaging and duplex ultrasound in diagnosis and management. J Urol 1993;149:1272-5.

65. da Silva Gaspar SR, Ferreira ND, Oliveira T, et al. Magnetic resonance imaging and pelvic fracture urethral injuries. Urology 2017;110:9-15.

66. Antonini G, Vicini P, Sansalone S, et al. Penile fracture: penoscrotal approach with degloving of penis after Magnetic Resonance Imaging (MRI). Arch Ital Urol Androl 2014;86:39-40.

67. Bernhardt TM, Rapp-Bernhardt U. Virtual cystoscopy of the bladder based on CT and MRI data. Abdom Imaging 2001;26:325-32.

68. Buthiau D, Antoine E, Piette JC, et al. Virtual tracheobronchial endoscopy: educational and diagnostic value. Surg Radiol Anat 1996;18:125-31.
69. Battista G, Sassi C, Schiavina R, et al. Computerized tomography virtual endoscopy in evaluation of upper urinary tract tumors: initial experience. Abdom Imaging 2009;34:107-12.

70. Rodenwaldt J, Kopka L, Roedel R, et al. 3D virtual endoscopy of the upper airway: optimization of the scan parameters in a cadaver phantom and clinical assessment. J Comput Assist Tomogr 1997;21:405-11.

71. Ahlquist DA, Hara AK, Johnson CD. Computed tomographic colography and virtual colonoscopy. Gastrointest Endosc Clin N Am 1997;7:439-52.

72. Gessner CE, Jowell PS, Baillie J. Novel methods for endoscopic training. Gastrointest Endosc Clin N Am 1995;5:323-36.

73. Izumi K, Kawanishi Y, Muguruma H, et al. Virtual cavernoscopy: a novel diagnostic tool for use in the corpus cavernosal lumen in patients with erectile dysfunction. BJU Int 2011;108:1316-20.

74. Kawanishi $Y$, Izumi K, Muguruma H, et al. Threedimensional CT cavernosography: reconsidering venous ligation surgery on the basis of the modern technology. BJU Int 2011;107:1442-6.

75. Gao QQ, Chen JH, Chen Y, et al. Dynamic infusion cavernosometry and cavernosography for classifying venous erectile dysfunction and its significance for individual treatment. Chin Med J (Engl) 2019;132:405-10.

76. Michal V, Pospíchal J. Phalloarteriography in the diagnosis of erectile impotence. World J Surg 1978;2:239-48.

77. Glina S, Ghanem H. SOP: corpus cavernosum assessment (cavernosography/cavernosometry). J Sex Med 2013;10:111-4.

78. Mulhall JP, Abdel MA, Abobakr R, et al. Improving the accuracy of vascular testing in impotent men: correcting hemodynamic alterations using a vasoactive medication redosing schedule. J Urol 2001;166:923-6.

79. Vardi Y, Glina S, Mulhall JP, et al. Cavernosometry: is it a dinosaur? J Sex Med 2008;5:760-4.

80. Gennisson JL, Deffieux T, Fink M, et al. Ultrasound elastography: principles and techniques. Diagn Interv Imaging 2013;94:487-95.

81. Sigrist RMS, Liau J, Kaffas AE, et al. Ultrasound elastography: review of techniques and clinical applications. Theranostics 2017;7:1303-29.

82. Cui A, Xu L, Mu J, et al. The role of shear wave elastography on evaluation of the rigidity changes of corpus cavernosum penis in venogenic erectile dysfunction. Eur J Radiol 2018;103:1-5.

83. Augustin HG, Koh GY. Organotypic vasculature: From 
descriptive heterogeneity to functional pathophysiology. Science 2017;357:eaal2379.

84. Gokce N, Keaney JF Jr, Hunter LM, et al. Risk stratification for postoperative cardiovascular events via noninvasive assessment of endothelial function: a prospective study. Circulation 2002;105:1567-72.

85. Rubinshtein R, Kuvin JT, Soffler M, et al. Assessment of endothelial function by non-invasive peripheral arterial tonometry predicts late cardiovascular adverse events. Eur Heart J 2010;31:1142-8.

86. Hamburg NM, Keyes MJ, Larson MG, et al. Crosssectional relations of digital vascular function to cardiovascular risk factors in the Framingham Heart Study. Circulation 2008;117:2467-74.

87. Bonetti PO, Pumper GM, Higano ST, et al. Noninvasive identification of patients with early coronary atherosclerosis by assessment of digital reactive hyperemia. J Am Coll Cardiol 2004;44:2137-41.

88. Kovac JR, Gomez L, Smith RP, et al. Measurement of endothelial dysfunction via peripheral arterial tonometry predicts vasculogenic erectile dysfunction. Int J Impot Res
2014;26:218-22.

89. Mehta A, Miner M, Sigman M. Assessment of EndoPAT scores in men with vasculogenic and non-vasculogenic erectile dysfunction. Int J Clin Pract 2013;67:46-51.

90. Beniczky S, Conradsen I, Henning O, et al. Automated real-time detection of tonic-clonic seizures using a wearable EMG device. Neurology 2018;90:e428-34.

91. Chan PH, Wong CK, Poh YC, et al. Diagnostic performance of a smartphone-based photoplethysmographic application for atrial fibrillation screening in a primary care setting. J Am Heart Assoc 2016;5:e003428.

92. Tison GH, Sanchez JM, Ballinger B, et al. Passive detection of atrial fibrillation using a commercially available smartwatch. JAMA Cardiol 2018;3:409-16.

93. Steinberg BA, Piccini JP. Screening for atrial fibrillation with a wearable device. JAMA 2018;320:139-41.

94. Qin F, Gao L, Qian SQ, et al. Advantages and limitations of sleep-related erection and rigidity monitoring: a review. Int J Impot Res 2018;30:192-201.
Cite this article as: Ma M, Yu B, Qin F, Yuan J. Current approaches to the diagnosis of vascular erectile dysfunction. Transl Androl Urol 2020;9(2):709-721. doi: 10.21037/ tau.2020.03.10 